\title{
Challenges in Mobile Teaching and Safety - A Case Study
}

\author{
Birgy Lorenz ${ }^{1}$ and Kaido Kikkas ${ }^{1,2}$ \\ ${ }^{1}$ Institute of Informatics, Tallinn University, Narva Road 25, 10120 Tallinn, Estonia \\ ${ }^{2}$ Estonian Information Technology College, Raja St 4C, 12616 Tallinn, Estonia \\ \{Birgy.Lorenz, Kaido.Kikkas\}@tlu.ee
}

\begin{abstract}
This paper is based on two studies about mobile learning in one secondary school in Estonia. The main question for this research was how should schools harness the increasing use of mobile phones, tablets at home in order to make it also beneficial for the schools? What are the emerging trends in mobile devices security that schools are facing when introducing m-learning to students? According to our findings, Estonian schools face various problems which must be addressed before any serious attempt at m-learning is made.
\end{abstract}

Keywords: mobile safety, didactics, mobile learning, integrated innovation, teacher attitudes.

\section{Background}

\subsection{School and Home Today}

The ITU Statistics from 2009 shows that $8 \%$ of the global population is using fixedline broadband and 14\% mobile broadband [9]. The Pisa 2009 results in Estonia reports higher usage of ICT tools at home (96\%) than at school (53\%). Students who use ICT and mobile phones just for leisure tend to get lower results than those who use ICT also for home- or classwork [14].

Despite the increasing use of mobile gadgets, availability to exploit these technologies and opportunities in real classrooms usually remains low because K12 education still focuses on laptops instead of mobile devices [6]. There is ongoing debate about whether schools should allow mobile phones, tablets to the classroom or not. Teachers say they need new methods and didactics before opening learning to mobile technologies, what students already experience every day [23]. There are several studies about edutainment using ICT and portable solutions in education [19]; however, the use of mobile phones and tablets is still emerging in education in the area of implementations [16].

Since the beginning of 2000, the European Commission has funded m-learning projects in three categories: Authoring and publishing, Delivery and Tracking, Content Development. The main goal of R\&D was aimed at young adults aged 16-24 [15]. Over the dozen years, E-learning has changed from sharing documents to 
co-working at creating the document from the start, from a closed system to an open one - the m-tools will further allow to experience that anyplace and anytime [1]. There are studies about pedagogical aspects of m-learning [12], engaging and measuring [7] as well work-based learning environments [2].

While the trends for the next decade have been promising, including the fusion of e-learning, m-learning and social networking, personal learning experience, tablets and cloud computing, some of them also raise caution - with the cloud-based data and high-speed mobile broadband to connect to it, security will become a much bigger issue [8].

M-learning is not yet implemented on the K-12 level in Estonia, but there are several good initiatives from Tallinn University Centre for Educational Technology for training teachers [11] and Estonian Information Technology College opened a software development laboratory for mobile devices [20] in 2011. Still, the training in these areas is lacking continuity. As Tiger Leap Foundation (foundation whose main purpose is to implement new technologies into schools in Estonia) has pointed out that mobile software should be in Estonian language rather than English to get better implementations for secondary schools. The cost of hardware and broadband has also been mentioned as a reason why m-learning is not implemented at schools yet [24].

There have been some studies about implementing m-learning or promoting it to children, e.g. Baker et al. [3] [5]. They list various practices used worldwide, but also outline new challenges, e.g. children becoming more of a researchers and publishers than consumers or information [10].

\subsection{Area of m-safety}

As tablets and mobile devices become ubiquitous, the safety risks also evolve. These could be divided into three categories: a) technical risks, related to how the mobile phone works (data protection, PINs/fingerprints, avoiding malware etc.), [4] [26] b) behavioral risks, related to users' habits and awareness (what to download, what to do when the phone is lost etc.) [25] [17] [22] c) policy risks, related to either too lax or too restrictive regulations (e.g. forbidding the use of phone or WiFi completely even when it is needed to teach or study) [21].

Some of the key differences in m-and e-safety are noted by Andero Sepp, an Estonian e-police official: first ignorance can be costly. Paid services, downloading virtual non-free gadgets, accidental roaming can result in a large bill. Secondly it is crucial to understand that not everything is meant to be shared and it is necessary to ask permission before taking e.g. a picture. On the other hand, crimes made with $\mathrm{m}$-devices are easier to detect as mobile operators gather information about the phone (location etc.). At the moment, mobile devices do have fewer viruses than ordinary computers. This also means that people are less aware of security.

We note that the studies about m-learning at school tend to focus on positive aspects like inclusiveness, flexibility and variability [18] [13]. The potential threats to e-safety are studied remarkably less. 


\section{Methods}

Our study focused on fifth- to ninth-grade students. We used survey, interview and observation methods. Most of the quantitative data was collected by means of closed questions or Likert scale options. The questionnaire and interview also included some open questions that concerned mainly about specific addressed questions. The study was carried out twice (2009 and 2012) at the same school.

Stage I In 2009, the participants were 153 students, $47 \%$ girls and $54 \%$ boys (46 from grades 5-6 and 107 from grades 7-9). 51\% of all students from grades 5-9 took part in the survey. In the follow-up in 2012 the number of participants was $156-80$ girls (19 from grades 5-6 and 61 from grades 7-9 - referred to as G1 and G2 respectively) and 76 boys (22 from grades 5-6 and 54 from grades 7-9 - referred to as B1 and B2 respectively). This time, the participants formed $36 \%$ of the student population.

Stage II - learning exercises and observation. We used 3 exercises in 2009 and 5 in 2012 to test how students were able to use mobile devices in school environment as a tool for working with curricular assignments in two months' time.

Stage III - an interview with a diverse choice of respondents from older age groups (18 students from grades 10-11, 6 teachers and in 2012 also 32 Master students from Tallinn University).

Stage IV - a group interview with 14 teachers conducted during an introductory course on m-learning in spring 2012.

\section{Results}

The results from the assignments reveal that in 2009 there were only 1-3 phones in every class that were useful as a learning device - by 2012 a half or more of the students have that opportunity. It is interesting that even when students use mobile every day still feel that mobile phone is not a learning device. The same idea was also expressed by teachers.

In 2009 students preferred to use photo camera to take pictures or videos. They were proud to appear in the video and share it to the world. 2012 students were more active using smartphones, but they were not interested to appear on the video anymore, the agreed solution was that they filmed hands and dolls or other props.

In 2009, finding software was more difficult due to different operating systems and abundance of software errors. By 2012 there are three major providers of apps. The numbers of available Estonian language apps as well as the applications that can be used in educational setting have increased a lot.

Results from the survey reveal that $201213 \%$ of respondents use calling cards. The biggest difference between the card users in different factions was between B1 (17\%) and others (10-12\%). New gadgets are mostly given to younger children, the difference between older is 5-8\% depending of the gender. The main reason to have a phone is said to be reachable for parents $(70 \%)$ and others $(86 \%)$, phone is a status indicator to only $7 \%$ of students, it has raised $4 \%$. 
Girls have more numbers recorded on the phone than boys. Older students have more of them (the difference with the younger age group is 27\%). The numbers recorded belong mostly to the family $(87 \%)$, friends $(76 \%)$, classmates $(88 \%)$, but also teachers $(31 \%)$, casual acquaintances $(30 \%)$, companies or other $(6 \%)$ and strangers $(20 \%)$. In particular, B1 $(27 \%)$ and G2 (23\%) keep more strangers' numbers than others (15-16\%). Compared to 2009, having strangers' numbers in one's phone is risen by $8 \%$ while the parental interest and control over the content has stayed the same $-3 / 4$ of parents have never asked to check their children's phones.

Older students spend more time in social networking (13\%) and direct communication (10\%) than younger. Girls tend to listen to music (17\%) and send SMS more than boys, especially notable is the difference between G1 (23\%) and others. Compared to 2009 , the regularity of using the phone as an internet device has risen from $9 \%$ to $64 \%$ and smartphone-related skills (e.g. watching videos, listening to music, using online social network, sending e-mail or using direct communication) have risen from $24 \%$ to $52 \%$.

$50 \%$ of students have used phone as a learning device, G2 leads in this sense. The phone skills analysis reveals that $54 \%$ of students play games coming with the phone. Gaming is more important to B1 - $77 \%$ play games that come with the phone and $27 \%$ play also Internet games, older boys (B2) would download most of the new games. $31 \%$ of $\mathrm{G} 2$ and $32 \%$ of B1 think about their selves as routine gamers.

Mobile services are of more interest to girls (23\%), but $23 \%$ of B1 having tried it out, just like calling to TV or radio programs. Calling to adult phone lines and services is more interest to the B group $-18 \%$ have already tried it. It is more of interest to B1. Other fee-based services like wallpapers, music, videos, games, other services or buying things over mobile phone are more common among younger students.

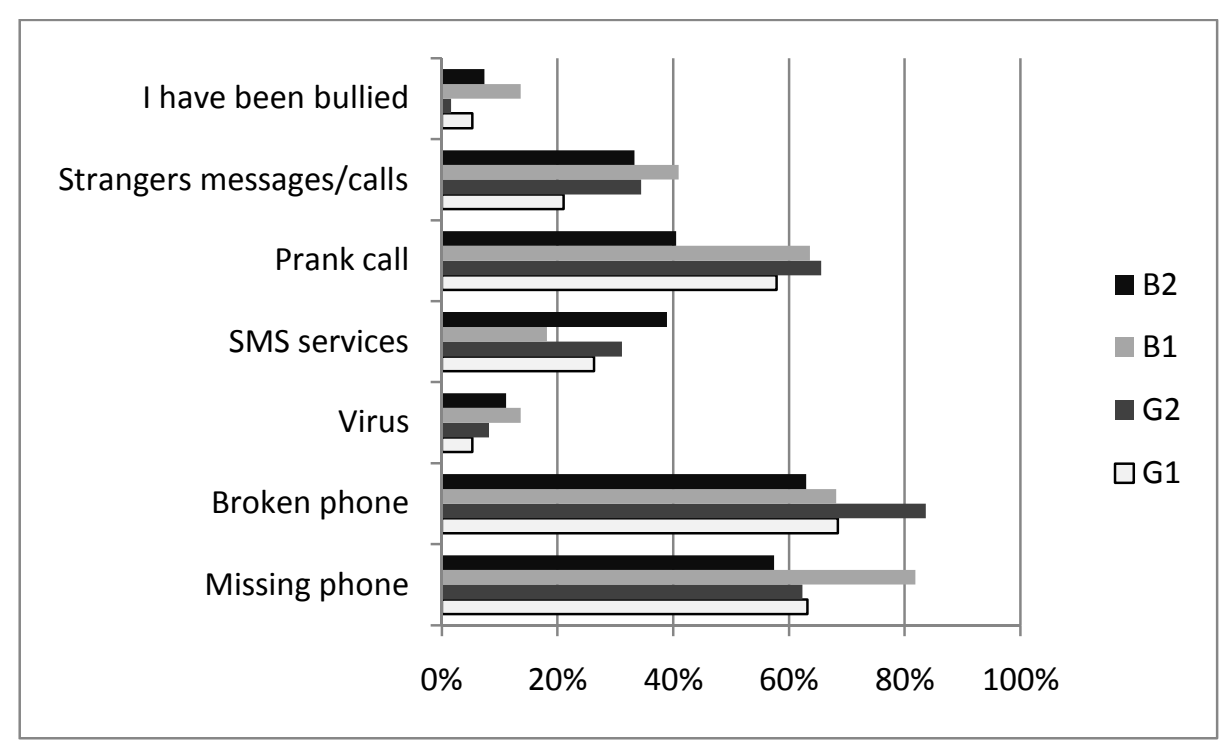

Fig. 1. What problems have risen of using phone 2012? 
Regarding other unpleasant cases all the numbers have raised from 2009 compared to 2012 . $15 \%$ more phones get lost, there are $31 \%$ more broken phones, $4 \%$ more viruses, $43 \%$ more prank calls (see more results and diagrams go to goo.gl/C4nD1). To see 2012 results look at the Fig 1.

The M-training for students revealed strong interest in hands-on participation they wanted to be active participants in the process, not just passive listeners.

The students were given the following tasks:

- $\quad$ using QR codes to enhance and promote literature reading and knowledge building and a "treasure hunting" game to find solutions to the e-safety problems;

- making videos and worksheets in math using real life situations;

- finding hidden pupils using only mobile phones (and only up to 12 yes/no answers were allowed);

- learning about 10th anniversary of the Euro using the Euro Coins application on Android;

- finding and identifying animal tracks in snow using an Estonian mobile application “Kes käis?” (Who Walked Here?);

- tagging problematic places near the school, e.g. trash, dangerous traffic locations like big piles of snow in the pedestrian area etc.

Students were also tasked to find and analyze mobile applications for education to use in teaching different subjects. The top three subjects were math and science, arts and music. The students emphasized that the programs should be in Estonian, but actually managed well with English apps as well.

The M-learning discussion group of teachers displayed sincere interest in these tools, even if only two participants did already own the smartphone. The interest increased after seeing and feeling that the mobile phone is in fact very intuitive and there were a lot of programs to discover in the Market application. Discussing the challenging part they pointed out that to really understand the m-world they should have the option to own a tablet or smartphone themselves. They also wanted to have examples of worksheets and guidelines how to build up lessons in a situation where every student or student group is in a different stage in his/her learning. Also the participants tended to support the idea that students should use their own gadget (as opposed to school-owned) at school. In this case, the teacher would have less responsibilities (e.g. to distribute tools at the beginning of a lesson, maintenance, accountability in case of misuse). In fact, there was little difference between teachers and students.

In the three areas of m-safety we interviewed 3 groups of people: gymnasium students, teachers and ICT students. Results reveal both differences and similarities in opinions and fears.

In the technical sense all groups were worried about accidental roaming expenses. The ICT students were divided in whether to use passcode or finger lock (to use it or not), as the gymnasium students and teachers were in the favor of it. Some ICT students suggested that people should install a tracking program to their phone so when a thief would use the phone they may get their phone back. 
In the behavioral sector they listed a lot of problems: activating paid services, stolen or missing phone, bullying, when and where and how long to use the phone, but usually all the problems were stated as moderate - reportedly it either usually don't happen to them or it is somebody else's problem.

In school policy sector, the restriction of school resources mirrored different understandings - the teachers pointed out problems with school policy to use mobile devices, while students thought it was their constitutional right to have access to the networks. Using their own mobile broadband connection (as opposed to the schools) was not considered a problem by anybody. Concerning awareness training and introducing m-learning to students, the students suggested that teachers should implement new technologies in educational way; teachers said that they did not have proper tools and training to do it, and it rather should be a responsibility for parents.

\section{Discussion}

Over the last three years, the challenges have increased as the use of smartphones, tablets has skyrocketed due to the increasing competition between service providers and phone manufacturers, as there is a lack of training in this field and supervision of students by their parents has stayed the same (i.e. very low). Students know how to make use of the new features offered by new gadgets - download, upload, share etc. At the same time, neither teachers nor parents are able to keep pace with them.

Schools should regulate how the m-tools are used in the class. When the teacher is not prepared to use these tools then he/she will not be pleased and the quality of teaching will be low. The teacher may view mobile phones, tablets as a threat to their existence because the students can go online and look for answers and undermine their position. Younger teachers using smartphones themselves are more willing to try it out in order to learn more about their phones.

The findings of the study confirmed that there is interest in using mobile learning in math, science and art classes. Students and teachers do not usually see m-learning as a part of their curriculum, but after practical experiences their fears start to vanish and they were more active and in control of their learning process.

The students' positive confidence using mobile phones has improved the results, raised interest in participating in math and science classes and also their willingness to do their mobile project related homework (the more exact impact is being tested yet). These findings lead to the conclusion that implementing mobile learning into school life gives better results than restricting it. We noticed that the participants still feel somewhat uneasy due to the urge to succeed at once. So our recommendation is to give a lot of feedback to students and teachers - discuss what went wrong and how the problems could be overcome next time.

From the study we see also that there are too many strangers in children's phonebook $(20 \%)$. Sometimes the strangers will appear after synchronizing phones with Facebook, but that also indicates that those children accept everybody as their friend on the Net. Also we found out that $18 \%$ of the boys have tried calling to adult services. It seems too easy to do that. Service providers can offer parents solutions which can block children's access to several services. It is possible in UK and US, 
but in Estonia providers are not interested in implementing such features as 'no parent has ever asked that'. A visible problem is also the rise of prank calls and bullying. Even if children say it is hardly more than a joke then after discussing these issues more deeply they admit that both bullying and cyber-bullying are an everyday problem.

A major problem with mobile phones, tablets in Pelgulinna Gymnasium is the possible accidental activation of paid services, because of the direct loss of money involved - school wanting to implement m-learning should seriously address the issue as well what are listed here:

Problem 1: in the purely technical sense, students are better equipped than schools. At the same time, they are unable to use the technology in a reasonable manner, as neither parents nor schools are unable to guide them. As the educational features are not shown to them, their activities tend to be limited to entertainment.

Problem 2: students are also left on their own in terms of e-safety and networking. As schools do not promote e-safety, the whole mobile technology has become a sort of „Wild West" - to make it worse, neither students nor their parents consider schools as reliable partners in this matter.

Problem 3: as a rule, the school and teachers deny any responsibility in these matters - most teachers claim it to be the responsibility of the parent who bought the gadget. When a training program is offered (e.g. by some international project), teachers are happy to accommodate them and when the training is complete, all problems are considered to be either solved or disappeared.

Problem 4: the digital divide will prevail until teachers acquire the necessary knowledge and skills - and also gain practical experience of the services used by students (e.g. Facebook). Teachers, being seriously overworked, typically do only as much as prescribed by the national curriculum - as e-safety is considered a pervasive topic not strictly related to any specific topic, it can be overlooked as 'irrelevant'.

Problem 5: the students are considered 'too smart' to need any additional training. According to the 2009 PISA study in Estonia [2], 2/3 of the school principals claimed to have no additional needs for ICT. Due to the national curriculum dropping the experimental ICT test in Grade 9, ICT seems to be not so important any more. Children are considered to 'be born with a mobile in their hands', but in reality, they lack a lot of crucial skills which result in education rather than technology.

Problem 6: for a while, the digital divide between smartphone users and those who cannot afford one may pose an issue. However, in a longer perspective this problem is likely to lose its urgency as smartphones are rapidly losing the luxury item status and becoming common tools (as both the prices of devices and related services are coming down). In the past, the same divide existed in computer use - right now, $98 \%$ of students in Pelgulinna Gymnasium are able to use computer at home. The comparison with an earlier study ( 2 years ago) shows that mobile phone ownership rates have increased a lot. 
We note that while this particular study focused on just one school, the results can mostly be applied to other urban schools (which involve a large majority of students) in Estonia as well. A larger survey is underway, but the preliminary results show strongly similar findings at large rural schools as well.

This study is still valuable to the Safer Internet in Estonia program that deals with e-safety issues and training in schools and kindergartens. The program so far has not yet focused on mobile technology and this is a big gap to be filled during the next stages of the program.

\section{Conclusion}

In analyzing problems with mobile phone use, we found the majority of the most crucial ones to be related to plain, everyday human behavioral issues: how to avoid large bills stemming from exceeding Internet quota, how to safely lend a phone to somebody, how to deal with paid services etc. Likewise, cyber bullying with phones, prank calls or strangers calling/texting can pose problems for children. As explained above, the parents and teachers are usually in a weak position to supervise students; they are usually left alone with these problems and have to develop their own strategies to deal with these matters.

The schools who have understood the circle of problems (having had awareness training or set up some regulations regarding the issue) are also in a better position to discover problems in advance, training parents and teachers. Those schools who forbid m- and e-learning as well as using laptops and phones at school premises just postpone the problem and banish it outside, while it keeps evolving in social networks and off the school time - and may finally outburst in a different way (in the worst case, a school shooting or any other comparably grave incident).

The students will only learn educational applications when these are taught them. The opportunity and resources of m-learning are seriously underexploited. There is a need for teaching materials and handbooks in Estonian language. Smartphones are new in the whole world, not only in Estonia - but there are several good examples and pilots to learn from. With half of the children already having these devices at home, we don't have the time to wait for the results of some multi-year academic studies. Teachers should have access to new technologies now rather than later. Schools should be open but at the same time also prepared for safety incidents.

Schools do have an option to open their classrooms to students' gadgets. Local authorities should provide broadband connection in the school area (WiFi). E-safety training should be mandatory for all teachers graduating from universities, be available via Tiger Leap training programs and also have an option to ask trainers or volunteers to visit the school. School leaders and government must provide teachers with modern technologies. Service providers could also provide more help to parents - both in well-designed services and better support in incident handling. 


\section{References}

1. 2009 Horizon Report (ID: CSD5612): In Educause (2009), http: / / www. educause.edu /ELI/2009HorizonReport/163616

2. Attwell, G.: Work based mobile learning environments: contributing to a socio-cultural ecology of mobile learning. In: Pachler, N. (ed.) Mobile Learning in the Context of Transformation (2010); In Special Issue of International Journal of Mobile and Blended Learning

3. Baker, A., Krull, G., Mallinson, B.: Proposed Theoretical Model for M-Learning Adoption in Developing Countries. In: Proceedings mLearn Education, pp. 17-22 (2005)

4. Cheng, J., Wong, S.H.Y., Yang, H., Lu, S.: SmartSiren: Virus Detection and Alert for Smartphones. In: MobiSys 2007, San Juan, Puerto Rico, USA, June 11-14 (2007)

5. Ching, D., Shuler, C., Lewis, A., Levine, M.H.: Harnessing the Potential of Mobile Technologies for Children and Learning Mobile Technology for Children, pp. 23-42. Morgan Kaufmann (2009)

6. Dias, A., Carvalho, J., Keegan, D., Kismihok, G., Mileva, N., Nix, J., Rekkedal, T.: An Introduction to mobile learning. In: GISMA, Socrates Project "The Role of Mobile Learning in European Education" (2008)

7. Diaz, V.: Mobile Teaching and Learning: Engaging Students and Measuring Impact. Presentation at the 2010 EDUCAUSE Center for Applied Research Symposium, Carlsbad, CA, December 7 (2010), http: / / www . educause. edu / ecar

8. Gadd, R.: My mLearning Predictions for 2010. In: Mlearning Trends (2010), http://mlearningtrends.blogspot.com/2010/01/my-mlearningpredictions-for-2010.html

9. ITU Statistics: ICT Data and Statistics (IDS) (2009), http : / / www.itu.int/ict/statistics

10. Koszalka, T., Ntloedibe-Kuswani, G.S.: Literature on the safe and disruptive learning potential of mobile technologies Distance Education. Routledge Journals 31(2), 139-157 (2010)

11. Laanpere, M.: E-õppest m-õppeni. In: M-õuesõpe Lemill.net (2011), http://lemill.net/content/webpages/e-oppest-m-oppeni

12. Laurillard, D.: Pedagogical forms for mobile learning. In: Pachler, N. (ed.) Mobile Learning: Towards a Research Agenda. WLE Centre, IoE, London (2007)

13. Lam, P.H.-C.: Students' Voices: Enriching Learning Experiences through M-learning. In: IEEE International Conference on Wireless Mobile and Ubiquitous Technology in Education, pp. 171-176 (2010)

14. Lorenz, B.: Eesti õpilaste PISA 2009 IKT-alased küsimuste vastused vihjavad kasutamata ressurssidele koolides. In: National Exam and Qualificaton Centre Pisa Research results page (2011), http://uuringud.ekk.edu.ee/fileadmin/user_upload/ documents/PISA2009_IKT_analyys.PDF

15. M-learning project background. In: M-Learning Ultralab and Stac (2005), http: / / www.m-learning.org/archive/background. shtml

16. Mobile learning for expanding educational opportunities. Workshop Report. In: International Workshop on Mobile Learning for Expanding Educational Opportunities, Tokyo, Japan (2005)

17. Mobile phone safety. In: Physicians and Scientists for Responsible Application of Science and Technology (2011),

http://www.psrast.org/mobileng/mobilstarteng.htm

18. Prensky, M.: Digital Game-Based Learning. McGraw-Hill, New York (2011) 
19. Pozzi, F.: The impact of m-learning in school contexts: An "Inclusive" perspective. In: Stephanidis, C. (ed.) HCI 2007. LNCS, vol. 4556, pp. 748-755. Springer, Heidelberg (2007)

20. Puusaar, M.: IT Kolledžis avatakse mobiilseadmete tarkvaraarenduse labor. ITK Press Release (2011)

21. Sheperd, I.J., Reeves, B.: iPad or iFad - The reality of a paperless classroom. In: Mobility Conference, Abilene Christian University (2011)

22. Speak up 2010 report, National Findings. In: K-12 Students and Parents Project Tomorrow (2011)

23. Stockwell, G.: Investigating learner preparedness for and usage patterns for mobile learning. ReCALL 20/3, 253-270 (2008)

24. Zova, K.: Kohtumine teemal "e-õppevarast mobiilsete seadmetele". In: Tiigrihüppe Sihtasutus Protokoll (2012), http://goo.gl/41QjT

25. Tippett, N., Thompson, F., Smith, P.K.: Research on Cyberbullying: Key findings and practical suggestions. In: Bullying Special Edition Contributor (2011)

26. Westervelt, R.: Smartphone theft, loss outweighs malware risk, McAfee report finds. In: SearchSecurity (2011) 